\title{
Lifelong Learning as the Key Competency for Industry 4.0
}

\author{
Julie Čermáková ${ }^{1}$, Michal Houda ${ }^{2}$, Ladislav Rolínek ${ }^{3}$
}

\begin{abstract}
Pressure in most companies requires employers to implement new strategies for the development of competencies through employee lifelong learning, taking into account ethics in the conditions of Industry 4.0, which is a topic presented in the theoretical introduction of the paper. The article aims to identify the characteristics influencing the development of lifelong learning with regard to ethics in the conditions of Industry 4.0. To meet the objective of this article, a hypothesis was formulated to determine the statistical significance of particular characteristics of the key competency of lifelong learning. The results of the ANOVA test for the lifelong learning competency show that the respondents' answers vary depending on their age, the level and field of their education, and their position in the organization. In particular, the authors used linear regression to evaluate the impact of age, gender, field and level of education, job position, the tenure of this job position and the size of company. From the results of the linear regression, it can be stated that the generation aged above 41 years, middle management and specialists have the closer relationship to lifelong learning than the rest of the population.
\end{abstract}

Keywords: lifelong learning, ethic, Industry 4.0, human resources.

JEL Classification: O30, O32

\section{Introduction}

Caratozzolo et al. (2020) see a major challenge as the thrust of the fourth industrial revolution and the pressure of industry in this sector requires employers to develop and implement new workforce strategies with respect to the ethics of Industry 4.0. Current requirements must address the additional challenges associated with the planned technology obsolescence. This phenomenon has been a trigger for further workforce obsolescence in recent years, with devastating effects on many companies and educational institutions unprepared for these cataclysmic changes. Problems in the field of ethics emerged soon. Lifelong learning as an important competency for Industry 4.0 turned out to be the right solution.

According to Matt (2018), most previous studies on Industry 4.0 deal with technological or infrastructural aspects; surprisingly few focuses on human resources, ethics, and organizational aspects. According to a study conducted by the German Chamber of Industry and Commerce (DIHK, 2010), more than half of the executives surveyed see a future shortage of skilled workers.

In their study, Bay et al. (2020) describe that the fourth industrial revolution, also referred to as Industry 4.0, emerged with new information technologies. These technologies enable everhigher levels of potential to dramatically influence sustainable social, ethical and environmental development

\footnotetext{
${ }^{1}$ University of South Bohemia, Faculty of Economic, Department of Management, Studentská 13, České Budejovice CZ-370 05, Czech Republic, e-mail: cermaj21@ef.jcu.cz.

${ }^{2}$ University of South Bohemia, Faculty of Economic, Department of Applied Mathematics and Informatics, Studentská 13, České Budejovice CZ-370 05, Czech Republic e-mail: houda@ef.jcu.cz.

${ }^{3}$ University of South Bohemia, Faculty of Economic, Department of Management, Studentská 13, České Budejovice CZ-370 05, Czech Republic e-mail: rolinek@ef.jcu.cz.
} 
However, according to Kurt (2019), the potential impacts of Industry 4.0 on labour markets still remain an area that has not been sufficiently examined. Industry 4.0 is expected to lead to technological unemployment due to the changing structure of employment and to bring new structural problems in terms of unemployment, ethics and labour relations. Similarly, automation and robotic production is expected to deeply affect the unskilled labour force and to cause a critical decrease in the workforce from the vulnerable groups of society, i.e., women, migrants, youth and elderly. On the other hand, according to Ras et al. (2017), many positions for skilled jobs have not been discovered yet.

The authors of the article fully agree with the statement of Ras et al., (2017) who claim that "In the era of Industry 4.0, the workforce is changing from being production-centric to being knowledge- and data-driven", which will have a significant impact on work ethics." According to Arntz (2016), the Organization for Economic Co-operation and Development (OECD) can already automate at least $9 \%$ of all jobs today. The expected changes in working life are specified in a study by Kurt (2019):

- the need for unskilled labour will be reduced,

- the need for a skilled workforce and digital skills will increase,

- new professions and jobs will replace lost jobs and many new job opportunities will emerge

- the importance of flexible structures with the ability to respond quickly to changes in working conditions will grow,

- there will be a transformation in the social and ethical structure,

- vocational training and lifelong learning concepts will become more important facing cyber security risks, wages for skilled workers will increase.

Based on the above, the authors point out the maximum responsibility of each individual for a lifelong process of self-education that does not end with schooling.

As reported by Mishra et al., (2020) Industrial Revolution 4.0 built on the technological inventions of the Third Industrial Revolution replaces and even eliminates jobs at a higher rate. The report of the World Economic Forum (WEF) entitled The Future of Jobs states that $65 \%$ of children entering primary schools today will eventually work in jobs that do not yet exist. As Schwab (2016) states, the Industrial Revolution 4.0 can fundamentally change the way we work, live, our ethics and interconnect.

Sustainability, Ethics and Industry 4.0 dominate the debates all over the world as the most pressing issues and challenges for society in general. According to Oesterreich\&Teuteberg (2016), the Fourth Industrial Revolution or Industry 4.0refers to the increasing digitization and automation of the production environment, as well as the creation of a digital value chain that enables the communication between products and their environment and business partners. These aspects require a high degree of compliance with ethical principles in the field of lifelong learning for Industry 4.0. 


\section{Literature review}

Based on relevant studies, the authors believe that lifelong learning is indispensable for Industry 4.0. In the World Economic Forum, Doepker (2019) in the report "Future of Jobs" predicts that 75 million jobs will be replaced by the year 2022 due to automation. During this period, however, other 133 million new jobs will be created in the global economy. Nevertheless, due to the lack of qualified human resources and the absence of the required qualifications, many of these posts will remain unfilled. This can be called a skills shortage, which has been a problem for the last decade, and it is not expected to be solved soon. This also poses the problem in terms of ethics in this area. In most cases, workers who lose their current job will not have the necessary qualifications to take up new positions that are already emerging and mostly unfilled. The problem will not be solved until the pressure put on everyone is high enough to make them "learn for life". It is not just about self-education, but also about attending retraining courses, seminars, workshops, learning to work with new digital technologies and so on.

Since 1972, "lifelong learning" has been mentioned along with "lifelong learning" and "learning society". These three concepts first appeared and were defined in the UNESCO report "Learning to Be" (Faure et al., 1972). The concept of lifelong learning was defined in the study by Chen et al. (2019), who claim that nowadays, it is necessary to focus on individual growth and everyday life in order to create a collective ideology of lifelong learning based on improving individual awareness.

Zhao \& Biesta (2012) believe that this idea is of international significance, the rich connotation, multiplex programs and complex branches. Its function has also been significantly highlighted, as lifelong learning can facilitate individuals to adapt to changing socioeconomic conditions in the field of ethics.

\section{Methods}

The aim of the article is to determine the characteristics that influence the development of lifelong learning of respondents with regard to ethics in conditions of Industry 4.0.

Based on the results of the quantitative study conducted between November 2018 and October 2020, the authors used structured data collected from 100 respondents (managers and employees) of selected professions in the Czech Republic. The respondents were selected from the sample of 142 questionnaires with a focus on their professional orientation and compliance with the conditions of Industry 4.0. The competency of lifelong learning is measured on the basis of self-assessment of the level in compliance with Industry 4.0. It is measured on an ordinal scale (the online questionnaire used a 10-point scale). The authors chose primarily an ANOVA test for linear regression models.

To achieve the objective of the paper, the following hypothesis was formulated to evaluate the impact of several characteristics of respondents (in particular their age, gender, field and level of education, job position in the company, tenure in the job position in the company, and the size of the company) on the key competency of lifelong learning for Industry 4.0:

$\mathrm{H}_{0}$ : The respondents' answers concerning lifelong learning competency for Industry 4.0 are identical regardless of the characteristics of respondents.

$\mathrm{H}_{1}$ : non $\mathrm{H}_{0}$ (The respondents' answers concerning lifelong learning competency for Industry 4.0 are different in at least one characteristic.) 
To verify the hypothesis, a standard analysis of variance (ANOVA) will be carried out for the competency of lifelong learning as a response variable, together with linear regression for the responses (the respondents' answers on the competency of lifelong learning in order to identify potential details of the relationship (Rencher \& Christensen, 2012). The results of the ANOVA and the linear regression are summarized in Section 0.

The methodology was chosen with regard to the statistical research based on the ANOVA test. According to Gueorguiev (2004), repeated measures ANOVA (rANOVA) is a commonly used statistical approach in proposals of repeated measurements. In such proposals, the repeated measurement factor (the qualitative independent variable) is a factor within the subject, while the dependent quantitative variable based on which each respondent is measured is a dependent variable. As with all statistical analyses, specific prerequisites should be met that justify the use of this test, as mentioned by Salkind et al. (2011). Their violations can slightly or significantly affect the results.

\section{Results}

Table 1 presents the ANOVA results for the competency of lifelong learningy: the respondents' answers differ according to the field and level of education attained, job position in the organization, and age. Based on the overall F-statistic of the linear regression model (see below) and $p$-value of 0.0012 , the hypothesis $\mathrm{H}_{0}$ is confirmed.

Table 1 Analysis of Variance and overall significance F-test for lifelong learning

\begin{tabular}{|c|c|c|c|c|c|c|}
\hline & $\mathrm{Df}$ & Sum $\mathrm{Sq}$ & Mean Sq & F value & $\operatorname{Pr}(>F)$ & \\
\hline gender & 1 & 0.938 & 0.9377 & 0.5626 & 0.45558 & \\
\hline age & 2 & 13.837 & 6.9187 & 4.1507 & 0.01951 & $*$ \\
\hline field & 2 & 12.500 & 6.2499 & 3.7494 & 0.02805 & $*$ \\
\hline education & 1 & 8.763 & 8.7635 & 5.2573 & 0.02466 & $*$ \\
\hline position & 3 & 19.772 & 6.5907 & 3.9538 & 0.01128 & $*$ \\
\hline tenure & 3 & 9.924 & 3.3081 & 1.9846 & 0.12351 & \\
\hline fsize & 3 & 7.006 & 2.3353 & 1.4010 & 0.24917 & \\
\hline Residuals & 75 & 125.017 & 1.6669 & & & \\
\hline
\end{tabular}

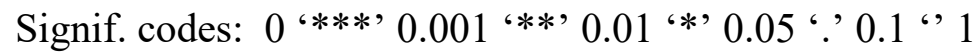

Source: Own processing

To get a further insight on how the respondents' characteristics influence their responses, we also performed the full estimation of the linear regression model with the following levels of individual factors as independent variables (the first level of each variable is always the base group of the given level):

- $\quad$ age levels: 21-30 years, 31-40 years (age. L), above 41 years (age. Q);

- field of formal education levels: economic sciences, humanities and pedagogical sciences, technical, natural and health sciences;

- education attained: secondary, and tertiary (university - education. L);

- job position levels: administration (e.g. accountant, technical assistant, etc.), middle management (e.g. the marketing manager), specialists (e.g. personnel specialist, etc.), and top management (directors, owners);

- tenure in the organization: less than 1 year, 1-5 years (tenure. L), 5-10 years (tenure. $Q$ ), more than 10 years (tenure.C); 
- the size of the organization: micro enterprises (up to 10 employees), small (11-50 employees, fsize. L), medium (51-250 employees, fsize. $Q$ ), and large (251 and more employees, fsize.C).

Table 2 Linear regression for lifelong learning

\begin{tabular}{|c|c|c|c|c|c|}
\hline & Estimate & std. Error & t value & $\operatorname{Pr}(>|t|)$ & \\
\hline (Intercept) & 5.73056 & 0.46158 & 12.415 & $<2 \mathrm{e}-16$ & $* *$ \\
\hline gender female & 0.40309 & 0.34173 & 1.180 & 0.24190 & \\
\hline age $31-40$ years & 0.34236 & 0.30433 & 1.125 & 0.26418 & \\
\hline age above 41 years & -0.60501 & 0.28962 & -2.089 & 0.04010 & * \\
\hline field humanities and education & 0.32101 & 0.44199 & 0.726 & 0.46993 & \\
\hline field technical, natural, health & 0.30522 & 0.36472 & 0.837 & 0.40532 & \\
\hline school level tertiary & 0.46670 & 0.24022 & 1.943 & 0.05579 & . \\
\hline position specialists & 1.17631 & 0.41787 & 2.815 & 0.00623 & ** \\
\hline position middle management & 1.51781 & 0.48671 & 3.119 & 0.00258 & $* *$ \\
\hline position top management & 1.44955 & 0.76335 & 1.899 & 0.06142 & . \\
\hline tenure in org. $1-5$ years & 0.38504 & 0.46221 & 0.833 & 0.40747 & \\
\hline tenure in org. $5-10$ years & -0.68918 & 0.40049 & -1.721 & 0.08940 & . \\
\hline tenure in org. 10 and more years & 0.39178 & 0.26406 & 1.484 & 0.14209 & \\
\hline size of the org. small & -0.04219 & 0.32711 & -0.129 & 0.89771 & \\
\hline size of the org. medium & 0.08609 & 0.33491 & 0.257 & 0.79785 & \\
\hline size of the org. large & 0.72140 & 0.36431 & 1.980 & 0.05135 & . \\
\hline Signif. codes: 0 '***, 0.001 6**, & 0.01 *' & 0.05 '. 0.1 & $1 ;, 1$ & & \\
\hline $\begin{array}{l}\text { esidual standard error: } 1.291 \text { on } \\
\text { lultiple R-squared: } 0.3678 \text {, A } \\
\text {-statistic: } 2.909 \text { on } 15 \text { and } 75 \text { D }\end{array}$ & $\begin{array}{l}75 \text { degrees } \\
\text { justed } \mathrm{R}-\mathrm{sc} \\
\mathrm{p} \text {-value: }\end{array}$ & $\begin{array}{l}\text { quared: } 0 . \\
: 0.001179\end{array}$ & 14 & & \\
\hline
\end{tabular}

Source: Own processing

The results of linear regression (see Table 2) show that the estimated difference between the expected score for the age group above 41 years (age. Q) compared to the base group $(-0.605$ points) achieves $p$-value of 0.040 . It follows that the expected score of the key competency of lifelong learning for the age group of 41 and older (other factors being fixed at base levels) is significantly different from the base group. In particular, the estimated score of the first group is 0.605 points lower. Furthermore, the estimated response for the age groups of 41 and older and $31-40$ years differ by $0.605+0.342=0.947$ points in favour of the latter group and is implicitly statistically significant, too. These estimated differences are adjusted for other factors included in the regression.

It follows from the above that the differences reported are solely due to the age; possible differences between the individual age groups caused by other factors (included in the regression model) are not considered. The higher average value for the age group of 41 and older ( 8.3 on the 10-point scale) compared to the average value for the age group of 31-40 years (8.4 points is caused by factors other than the age, as opposed to the negative estimated score difference of the first group. 
Other statistically significant coefficients concern the position in the organization: in particular, middle management level ( $p$-value of 0.003 ), and specialist level ( $p$-value of 0.006) or at least in comparison with the base group. The estimated differences in score are 1.518 and 1.176 points. The remaining coefficient (for the top management group) is insignificant, with $p$-value being 0.061 and the estimated difference in score of 1.450 points compared to the base group. The differences between the three groups are small and statistically insignificant (and thus not reported here). Again, the reported estimated differences are cleansed of the remaining factors included in the regression model. On average, the results of the questionnaire indicate that the workers on administrative positions evaluated the competency of lifelong learning worse (6.56 on the 10-point scale) than specialists (on average, 7.84 on the 10-point scale) and middle management (on average, 8.21 on the 10-point scale). In terms of job requirements in companies, middle management and specialists show more positive attitude to the competency of lifelong learning than administrative workers.

It shall also be noted that even two other factors (field and attained level of education) were identified as statistically significant in the ANOVA analysis; they are jointly significant and cannot be removed from the regression model. No individual differences between their levels could be demonstrated (with only a slightly significant $p$-value of 0.056 in the case of tertiary education). However, the scores may become important when compared with a group other than the base group.

\section{Discussion}

Research focusing on statistical survey concerning the competency of lifelong learning, ethics and Industry 4.0 has not conducted out. Several authors deal with the competency of lifelong learning and Industry 4.0, but without any comparison with the field of ethics. This research addresses all these areas - lifelong learning, Industry 4.0 and ethics. The views of some authors concerning some of these areas are presented below.

Vrchota et al. (2019) mention the importance of lifelong learning with constantly changing and evolving employee requirements. Education plays a primary role in terms of competitiveness in the labor market and in terms of the preparedness of the population for Industry 4.0. Lifelong learning is linked to the introduction of diversified pathways that will enable education of different age and social groups. Information technologies of Industry 4.0 play a key role in the employability in the labor market. Computer skills are indispensable in terms of personal and professional life. The level of these skills depends mainly on the age of the person, the economic level of the state, and is often related to IT equipment of households.

According to the Ministry of Industry and Trade (2019), it is important to consider the changes caused by the impact of the industrial revolution on employment and labor productivity, which affect the entire development of ethics in society and may be particularly threatening for less qualified individuals, but on the contrary may bring new qualification requirements for employment. Retraining and further education will become a necessity for those who want to continue to be successful in society.

Piwowar-Sulej (2020), Bercovici et al. (2019), Whysall et al. (2019) agree in the statement that the changes in business activities are associated with significant transformation in the process of training future economic employees and the development of expected employee competencies and changes in the labour market and human resources management and the related necessary changes in employee professional qualifications and competencies, in particular in the areas of digital skills, ethics and the process of continuous professional development. 


\section{Conclusion}

As for the specific characteristics of the competency of lifelong learning for Industry 4.0, a hypothesis was formulated to meet the objective of the paper. These characteristics include gender, age, field and level of education attained, job position in the company, tenure of this job position in the company and the size of the company.

Based on the results, the null hypothesis was rejected: the respondents' answers concerning the competency of lifelong learning for Industry 4.0 differ in at least one characteristic. The results show that the answers differ depending on the level of education attained, field of education, position in the organization and age. The coefficients of these characteristics were further examined by means of linear regression. On the basis of the results, the authors made the following conclusions.

Employees at the age of 41 and older tend to evaluate lifelong learning more positively with regard to the conditions of Industry 4.0 compared to younger employees (aged 21-30). The authors conclude that the reason for worse evaluation on the side of the younger employees aged 21-30 is often tertiary education and the fact that they do not connect the competency of lifelong learning with tertiary education. It follows from the responses that the evaluation from the side of the young generation is on average lower than in the case of employees aged 41 and older. This older age group is forced to deal with the competency of lifelong learning directly due to their profession. The characteristics of the job position in the organisation reflect a similar pattern of results. The authors conclude that administrative workers are not as often associated with lifelong learning as middle management and specialists who are forced to educate themselves throughout their professional lives.

The research was conducted on a sample of 100 representatives of companies with regard to the conditions of Industry 4.0. Further research could follow the results on a larger sample of respondents. This research could be used as a model for comparing the competency of lifelong learning for Industry 4.0 in the Czech Republic and abroad. For the purposes of research including a foreign country, specific criteria should be established, since there are differences e.g. between secondary school students in the Czech Republic and abroad. Further research may consider the use of objective data for more developed countries in comparison with less developed countries in terms of ethics.

\section{Acknowledgement}

The article was written within the research project GAJU 047/2019 / S "Business Management in the Conditions of Industry 4.0."

\section{References}

Arntz, Gregory, Zierahn (2016). The Risk of Automation for jobs in OECD countries OECD SEM Working Papers, 189.

Bay, C., Dallasega, P., Orzes, G., \& Sarkis, J. (2020). Industry 4.0 technologies assessment: A sustainability perspective. International Journal of Production Economics, 107776. doi: 10.1016/j.ijpe.2020.107776.

Bercovici, E. G., \& Bercovici, A. (2019). Israeli labor market and the Fourth Industrial Revolution. Amfiteatru Econ., 21, 884-895.

Caratozzolo, P., Sirkis, G., Piloto, C., \& Correa, M. (2020). Skills Obsolescence and Education Global Risks in the Fourth Industrial Revolution. IFEES World Engineering Education ForumGlobal Engineering Deans Council. DOI: 10.1109/WEEF-GEDC49885.2020.9293687. 
DIHK - Deutsche Industrie- und Handelskammertag (2010). Staff urgently wanted! Safeguarding the future - The challenge of the future, Berlin.

Doepker, M. (2019). Article on 5 ways students can graduate fully qualified for the Fourth Industrial Revolution. Available online: https://www.weforum.org/agenda/2019/01/howstudents-can-graduate-qualified-forfourth-industrial-revolution (accessed 9.3.2021).

Faure, E. et al. (1972). Learning to be: The world of education today and tomorrow - The report to UNESCO of the International Commission on the Development of Education. UNESCO, Paris.

Gueorguieva; Krystal (2004). "Move Over ANOVA". Arch Gen Psychiatry. 61 (3): 310-7. doi:10.1001/archpsyc.61.3.310. PMID 14993119.

Chen, Z., \& Liu, Y. (2019). The different style of lifelong learning in China and the USA based on influencing motivations and factors. International Journal of Educational Research, 95, 1325. https://doi.org/10.1016/j.ijer.2019.03.005.

Kurt, R. (2019). Industry 4.0 in Terms of Industrial Relations and Its Impacts on Labour Life. Procedia Computer Science, 158, 590-601. doi: 10.1016/j.procs.2019.09.093.

Matt, D. T., Orzes, G., Rauch, E., \& Dallasega, P. (2018). Urban production - A socially sustainable factory concept to overcome shortcomings of qualified workers in smart SMEs. Computers \& Industrial Engineering. doi: 10.1016/j.cie.2018.08.035.

Ministry of Industry and Trade (2019) Iniciativa Průmysl 4.0. Available online: http://www.nuv.cz/eqf/ iniciativy-prumysl-4-0-prace-4-0-a-vzdelavani-4-0 (accessed 16.02.2021).

Mishra, S. R., Mishra, T. K., Sanyal, G., Sarkar, A., \& Satapathy, S. C. (2020). Real time human action recognition using triggered frame extraction and a typical CNN heuristic. Pattern Recognition Letters, 135, 329-336. doi: 10.1016/j.patrec.2020.04.031.

Oesterreich \&Teuteberg (2016). Understanding the implications of digitisation and automation in the context of Industry 4.0: A triangulation approach and elements of a research agenda for the construction industry. Computers in Industry, 83, pp. 121-139.

Piwowar-Sulej, K. (2020). Human resource management in the context of Industry 4.0. Organ. Manag. Sci. Q., 1, 103-113.

Ras, Wild, Stahl, Baudet (2017). Bridging the skills gap of workers in industry 4.0 by human performance augmentation tools: Challenges and roadmap Proceedings of the 10th international conference on Pervasive technologies related to assistive environments, Rhodos, Greece (2017), pp. 428-432.

Rencher, Alvin C., \& Christensen, William F. (2012). Methods of Multivariate Analysis, Wiley Series in Probability and Statistics, 709 (3rd ed.), John Wiley \& Sons, p. 19, ISBN 9781118391679.

Schwab, K. (2016). The fourth industrial revolution: What it means and how to respond. World Economic Forum. Retrieved from https://www.weforum.org/agenda/2016/01/the-fourthindustrial-revolutionwhat-it-means-and-how-to-respond/

Green, S., \& Neil, S. (2011). Using SPSS for Windows and Macintosh: analyzing and understanding data (6th ed.). Boston: Prentice Hall. ISBN 978-0-205-02040-9.

Vrchota, J., Mařiková, M., Řehoř, P., Rolínek, L., \& Toušek, R. (2019). Human Resources Readiness for Industry 4.0. Journal of Open Innovation: Technology, Market, and Complexity, 6(1), 3. https://doi.org/10.3390/joitmc6010003. 
Whysall, Z., Owtram, M., \& Brittain, S. (2019). The new talent management challenges of Industry 4.0. J. Manag. Dev., 38, 118-129.

Zhao, K., \& Biesta, G. (2012). The moral dimension of lifelong learning: Giddens, Taylor, and the "Reflexive project of the self". Adult Education Quarterly, 62 (4), pp. 332-350. 